\title{
TECHNICAL EVOLUTION AND IDENTIFICATION OF RESIN-FILLED TURQUOISE
}

Ling Liu, Mingxing Yang, Yan Li, Jingru Di, Ruoxi Chen, Jia Liu, and Chong He

Zhushan County is the most abundant source of commercial turquoise in China's Hubei Province, where mass production has been ongoing for several decades. Chinese turquoise production and consumption have created a significant industry and promoted local economic prosperity and development. Treatment techniques for turquoise have been updated and changed rapidly, sometimes even monthly. Traditionally, rough materials are treated with resin to reduce their high porosity to improve processability, appearance, and stability. In this research, the characteristics of resin-filled turquoise were investigated by ultraviolet fluorescence, spectrofluorometry, and Fouriertransform infrared spectrometry. The differences in three-dimensional fluorescence patterns between untreated and resin-filled turquoise are reported for the first time. The three-dimensional fluorescence patterns along with the ultraviolet reactions and infrared spectra allow for the identification of this filling. Unlike untreated turquoise, the resin-filled turquoise samples had a strong and main emission peak centered at approximately $444 \mathrm{~nm}$ and a secondary emission shoulder at approximately $460 \mathrm{~nm}$ under approximately $372 \mathrm{~nm}$ wavelength excitation in this research. This study sheds light on resin filling processes by observing the essential features of 342 turquoise specimens after treatment. Resin filling can decrease the porosity of turquoise to improve its color and its value, and this study provides identification guidelines for gemologists and useful information on the resin-filling process.

T urquoise, a hydrated copper aluminum phosphate mineral $\left(\mathrm{CuAl}_{6}\left(\mathrm{PO}_{4}\right)_{4}(\mathrm{OH})_{8} \cdot 4 \mathrm{H}_{2} \mathrm{O}\right)$, has been appreciated as a valuable gem material worldwide for thousands of years. It has a wide range of colors, such as blue, blue-green, green, yellowish green, and greenish yellow. Among these colors, blue turquoise is the most popular and sought after in the commercial market (figure 1).

In the early 1980s, many residents of Shiyan City in China's Hubei Province owned turquoise, though few were conscious of its value. The locally produced turquoise was a great bargain at about US\$100$\$ 200 / \mathrm{kg}$. Moreover, small fragments were even used there as outdoor decorative materials in the 1980s (figure 2). In 2009, the local government suddenly realized the significance of its turquoise resources and started to manage mining. Since then, prices have soared because of limited turquoise resources and regulation of mining.

Generally, the portion of rough turquoise suitable for processing into fashioned gemstones is much less

See end of article for About the Authors and Acknowledgments.

Gems \& GemOlogy, Vol. 57, No. 1, pp. 22-35,

http://dx.doi.org/10.5741/GEMS.57.1.22

(C) 2021 Gemological Institute of America than $5 \%$ of the mined total. Most natural turquoise contains fissures, pores, matrix, or other defects (figure 3, left and center). Much of the porous turquoise (figure 3, right) is termed "pale" or "chalky." This ma-

\section{In Brief}

- High-quality natural turquoise is in high demand in the commercial market. Various advanced treatment techniques are performed on this material due to its intrinsic porosity. The ability to detect and identify treated turquoise is urgently needed because of the prevalence of constantly evolving treatment techniques in the marketplace.

- In this research, resin-filled turquoise displayed strong signals under long-wave ultraviolet radiation, as well as three-dimensional fluorescence patterns and infrared spectra associated with resin. Spectrofluorometry is a newly employed nondestructive technique for routine identification of turquoise treatment.

- Turquoise with pale to moderate color can show dramatic improvement in appearance and stability after pore filling treatment. Turquoise porosity drastically decreases when pores are filled with resin, thereby improving its appearance. 

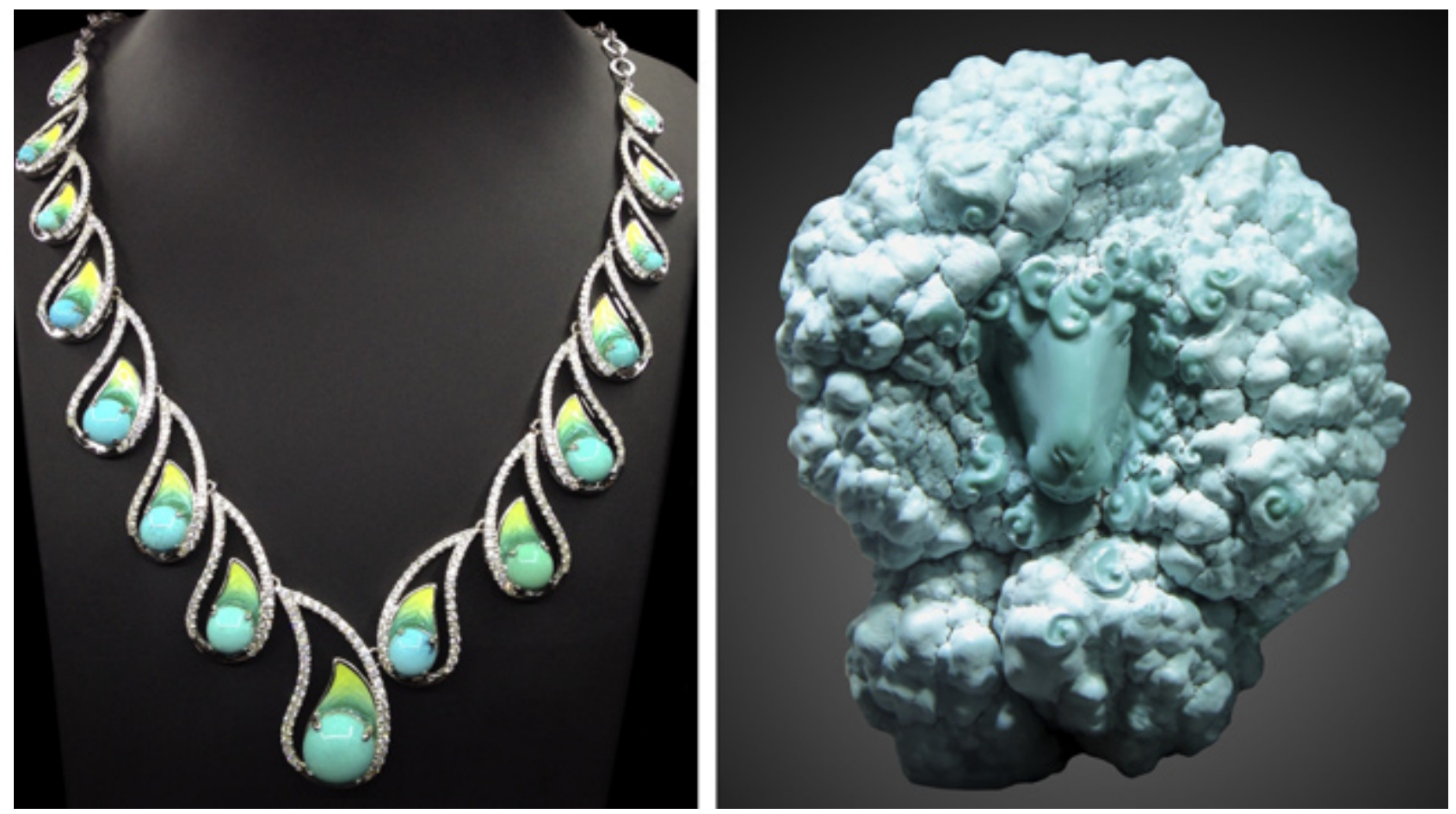

Figure 1. A necklace with inlaid blue turquoise (5-12 $\mathrm{mm}$ in length) and a turquoise sculpture (100 $\mathrm{mm}$ in height). The sculpture on the right was photographed at the Tiangong Award exhibition. Photos by Mingxing Yang.

terial's low hardness makes it unsuitable for processing, and it is often accompanied by low color saturation and numerous micrometer- to nanometer-sized pores. With daily wear, the color and luster of turquoise may change gradually from prolonged absorption of sweat and skin oil. Nevertheless, many Chinese turquoise enthusiasts and collectors are passionate about its natural appearance and variations.
As a porous cryptocrystalline aggregate, rough turquoise has been subjected to filling treatment to make it easier to process and improve its appearance and stability (Koivula et al., 1992; Choudhary, 2010; McClure et al., 2010). Filling treatment has been performed on a variety of low-quality gemstones with pores, fractures, or fissures. Examples include opal (Gambhir, 2001; Filin and Puzynin, 2009; Hu et al.,

Figure 2. Turquoise fragments $(0.2 \times 0.2 \mathrm{~cm}$ to $1.0 \times 1.3 \mathrm{~cm})$ were used as outdoor decorative materials in the $1980 \mathrm{~s}$ in Yun County, Hubei Province. Photos by Ling Liu.

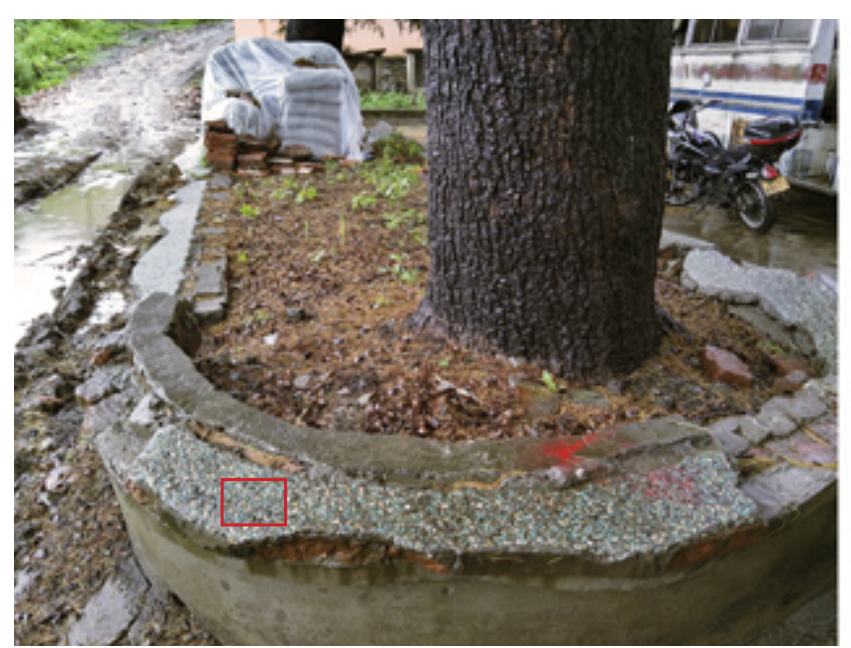

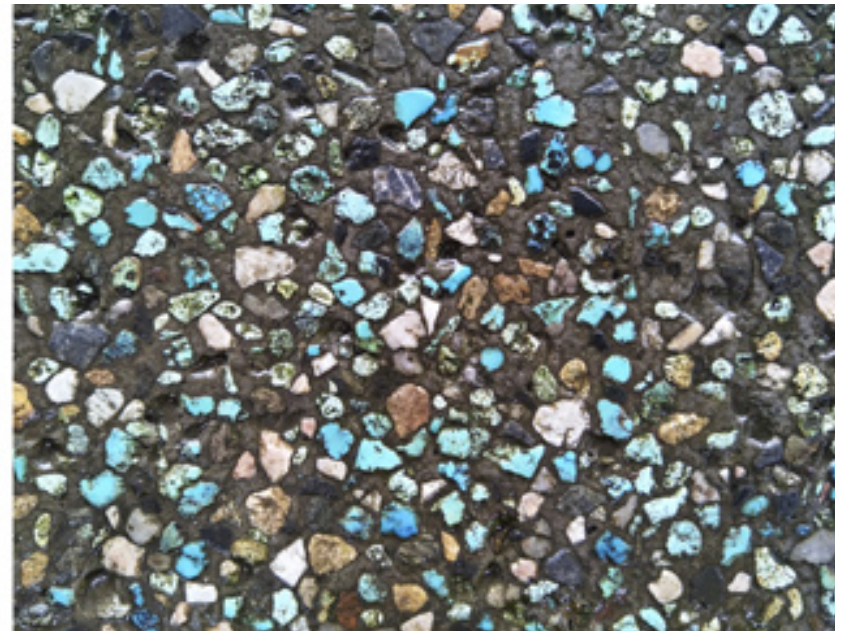

GEMS \& GEMOLOGY

SPRING 2021 

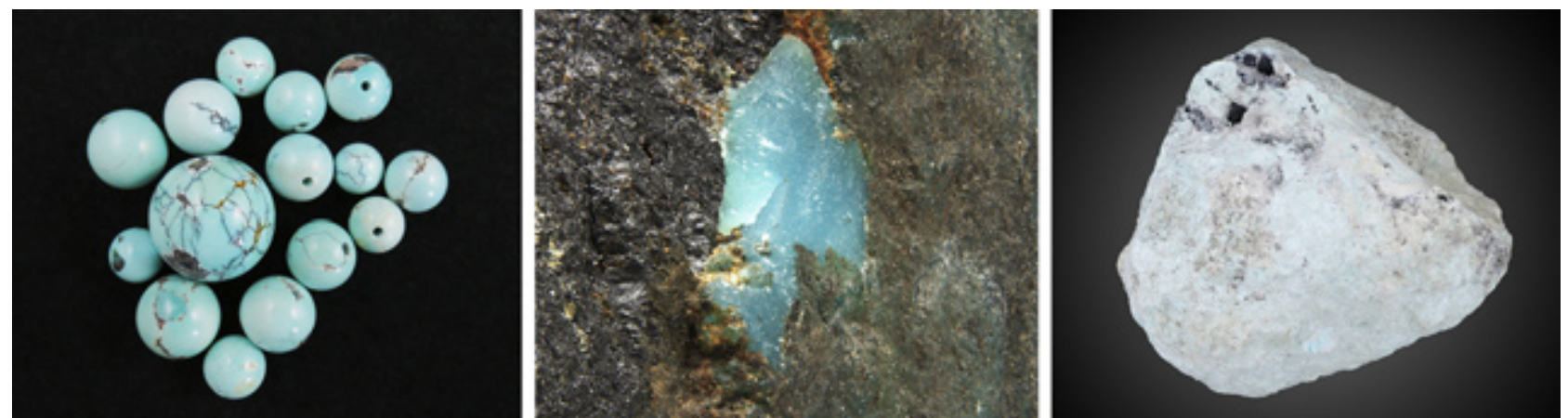

Figure 3. Left: Turquoise with fissures and pores (22.7 $\mathrm{g}$ total). Center: Turquoise surrounded by matrix (field of view $7.4 \mathrm{~mm}$ ). Right: "Pale" or "chalky" turquoise (298 g). Photos by Ling Liu.

2013), tourmaline (Deng et al., 2009), emerald (Kammerling et al., 1991; Johnson et al., 1999; Johnson, 2007), and ruby ("GAAJ Lab Alert," 2004; McClure et al., 2006).

In China, conventional pore fillers used for turquoise are wax and resin. The appearance and durability of "pale" or "chalky" turquoise can be greatly improved by pore filling to decrease its porosity (figure 4). Using this technique, porous material can be fully optimized to increase its value. Occasionally, however, treated turquoise products are unfavorable due to the material's uneven hardness. The resin agent permeates and infiltrates porous areas much more easily than the compact portion. Consequently, the porous portions develop a more saturated color than the compact portion after resin treatment. As a result, the resin-treated turquoise displays a mottled appearance with obvious and artificial boundaries after polishing (figure 5). Resin filling of material sold in China should be noted in a turquoise identification report according to the Chinese national testing standard.

Turquoise can also be impregnated with a mixture of resin, hardener, and colorant. However, such

Figure 4. A bracelet and necklace set with treated turquoise (37.17 g total). Photo by Ling Liu.

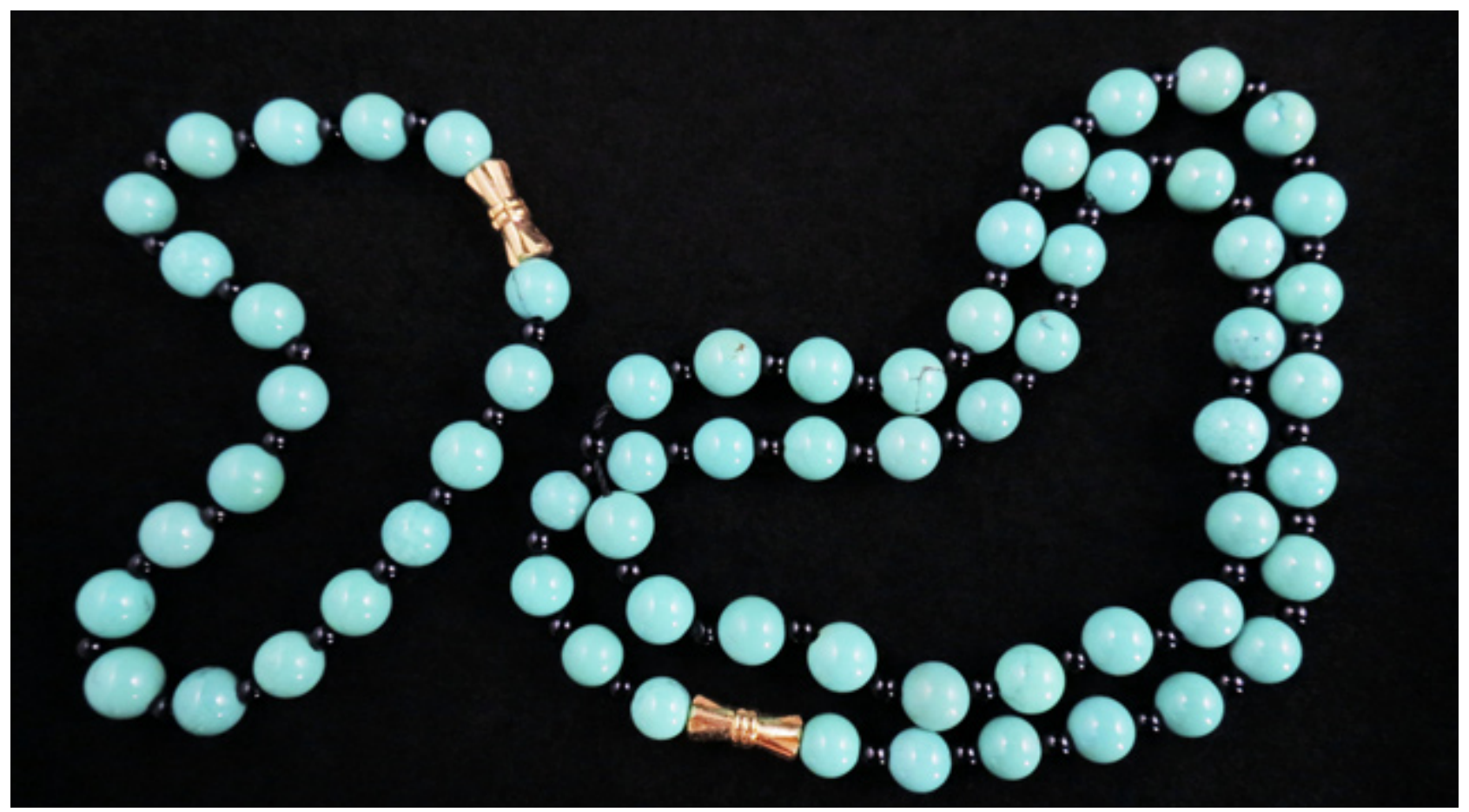



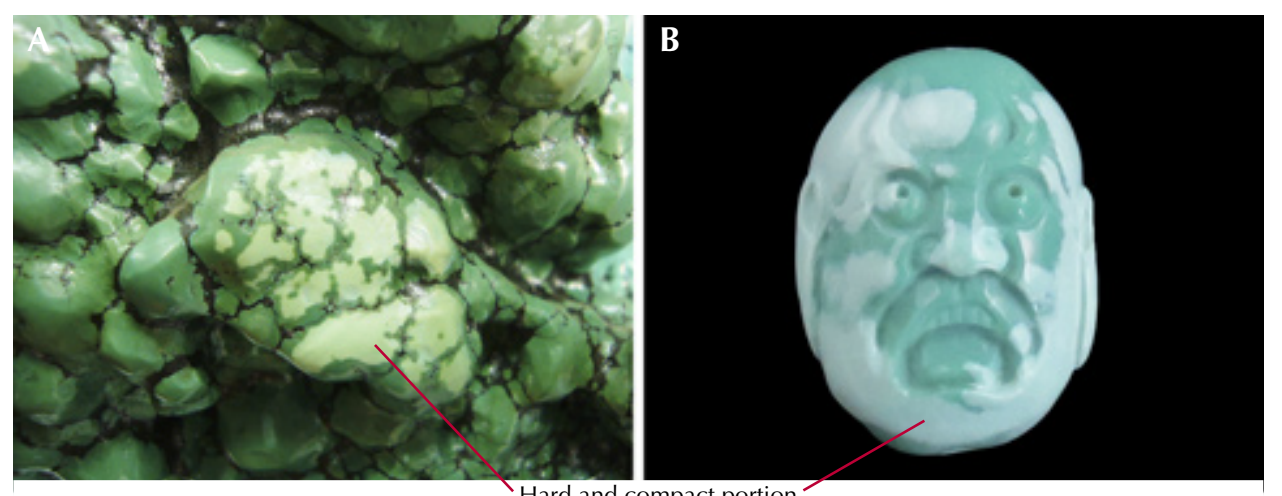

Figure 5. Turquoise with an unsatisfactory appearance after resin filling treatment. A: Close-up of a large ornament (field of view $90 \mathrm{~mm})$. B: A carved ornament $(3 \mathrm{~g})$. $C$ and $D$ : Two pendants (60 and $50 \mathrm{~mm}$ in length, respectively). The lightercolored portions are

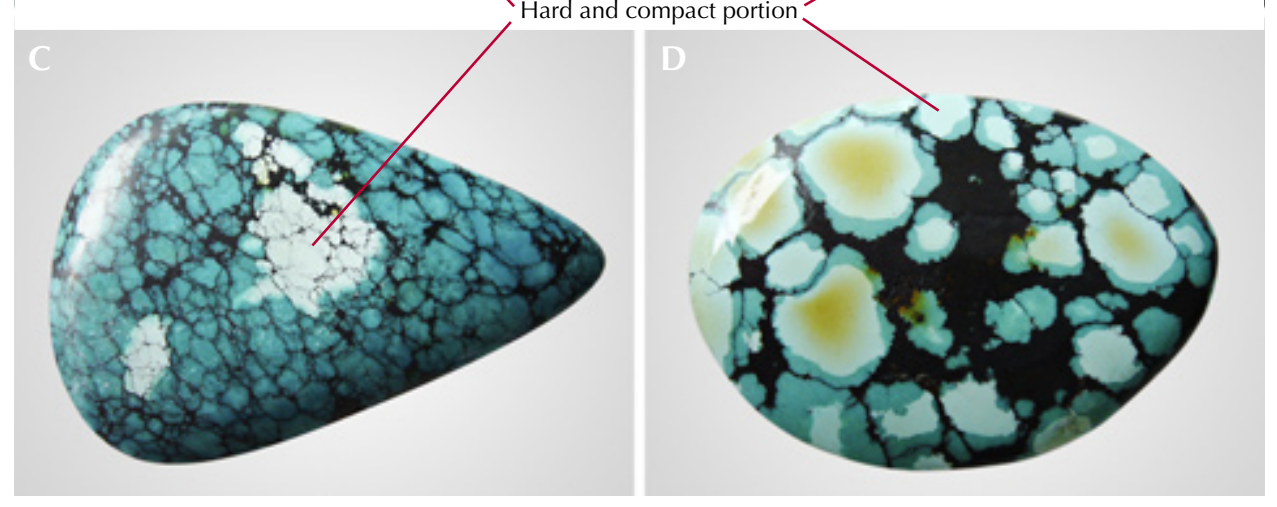
harder and more compact than the deeply colored portions before treatment, and therefore the resin treatment does not easily penetrate them. The artificial color boundaries generated during resin filling become obvious after polishing. Photos by Mingxing Yang and Ling Liu.

impregnation and dyeing treatment is unacceptable in the Chinese commercial trade. Additionally, the "Zachery" treatment developed in the United States can be applied to improve the color and polish of turquoise, which was first reported by $G \uplus G$ in 1999 (Fritsch et al., 1999). However, the specific equipment and agents used in the Zachery technique remain proprietary, and so far it has not been widely used in Hubei Province. Although Chinese manufacturers were initially unsure how this treatment works, they have tried to master the technology and succeeded in developing an electrochemical method (similar to the Zachery technique) to optimize not only blue turquoise, but also yellow and green materials. The thicker treated layer and saturated color produced by this electrochemical method are a significant improvement (Lin et al., 2019; Shen et al., 2018). Moreover, oiling is also widely applied to turquoise in the Chinese market today (Koivula et al., 1992; Hu et al., 2019). For a glossary of turquoise enhancement terminology, see box A.

Researchers have devoted great effort to the identification of treated turquoise, as well as various kinds of fillers such as resin, polymer, oil, plastic, and dyed substances (Lind et al., 1983; Chen et al., 2006; Moe et al., 2007; Chen et al., 2010a; Choudhary, 2010; McClure et al., 2010; Han et al., 2015; Bernardino et al., 2016; Zuo et al., 2017; Xu and Di,
2018; Hu et al., 2019; Liu et al., 2019; Xu and Yang, 2019). The treated examples mentioned above can be easily identified by different testing techniques, such as Raman and IR spectroscopy (Henn and Milisenda, 2005; Chen et al., 2006; Moe et al., 2007; Zuo et al., 2017), UV-Vis spectrophotometry (Han et al., 2015), energy-dispersive X-ray fluorescence (EDXRF; Fritsch et al., 1999|, and pyrolysis-gas chromatography-mass spectrometry (Py-GC-MS; Schwarzinger and Schwarzinger, 2017). An intense band at $\sim 1730 \mathrm{~cm}^{-1}$ is detected in the IR spectra of most organic-treated turquoise (i.e., polymer, plastic, or resin), which is assigned to the $\mathrm{C}=\mathrm{O}$ stretching vibration. Elevated potassium is detectable exclusively in Zacherytreated turquoise (Fritsch et al., 1999).

The usual analytical techniques, such as IR spectroscopy, are sensitive to organic compounds. Counterfeiters have cunningly applied new inorganic substances to achieve superior color, luster, texture, and porcelain-like quality to pass inspection and cater to consumer demand for high-quality turquoise. More recently, many new approaches to turquoise treatment have emerged in the market using various inorganic fillers, such as aluminum dihydrogen phosphate (Zhou and Yuan, 2008; Chen et al., 2010b) and sodium silicate (also called "glass

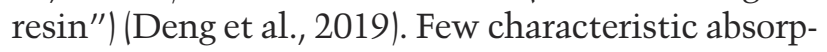
tions assignable to these fillers can be found in IR 


\section{Box A: Terminology of Turquoise Treatment TeChNiques}

Waxing: Turquoise (generally fashioned turquoise) is immersed in wax to coat its surface to enhance durability and appearance and prevent discoloration over time. This treatment is accepted in the trade.

Oiling: Turquoise is treated for several days or weeks by various types of oil (e.g., mineral or vegetable oil), which acts as a concealer and filler to hide superficial flaws (such as white spots) and decrease porosity for better color, appearance, and stability.

Dyeing: Turquoise is colored by various dyes or colored substances.

Resin filling: Under ambient conditions, resin and hardener are introduced into the pores of the turquoise to obtain a more stable material for processability and durability. With filling of the pores, the color of the turquoise improves because there is less light scattering.

Resin impregnation: Turquoise is impregnated with a combination of resin and hardener. The resulting altered color is dull and saturated. This process is different from resin filling. Both vacuum and pressure conditions are applied in the impregnation process but not in resin filling.

Resin impregnation and dyeing: Colorants are added and mixed with the resin and hardener. This treatment process is also performed under vacuum as well as pressure conditions, similar to resin impregnation.

Porcelain enhancement: A popular treatment technique that decreases the porosity of turquoise and improves the compactness, hardness, and luster without the use of organic polymers. Typically, this treatment involves filling turquoise with aluminum dihydrogen phosphate or sodium silicate. If turquoise is treated with phosphate substances, colorant could have been added if deemed necessary. If treated with sodium silicate, however, there is no addition of colorant.

Zachery treatment: Turquoise is treated with a potassium-containing compound for better stability and appearance. Its name refers to entrepreneurial electrical engineer James E. Zachery, who invented this process in the late 1980s (Fritsch et al., 1999).

Electrochemical method: Rough or fashioned turquoise is treated with electrolytes (usually containing potassium) based on electrochemical fundamentals (similar to the Zachery technique). The treated turquoise can achieve more saturated color not only on the surface but throughout the entire sample (Lin et al., 2019; Shen et al., 2018).

Yellow/black-fading: Turquoise is treated with chemical agents to get rid of black or yellow stain-like colors. spectra and X-ray diffraction patterns, although scanning electron microscopy (SEM) is capable of revealing the anomalous structural characteristics of turquoise treated with aluminum phosphate adhesive (Zhou and Yuan, 2008; Chen et al., 2010b). Furthermore, some special chemical agents are used to get rid of black or yellow stain-like colors. Industry sources call this technique "yellow/black-fading" treatment and claim these stained turquoise materials can display the desired blue color after processing. Further investigation is necessary for this new treatment. Because treatment techniques have evolved so rapidly in China, their identification remains a great challenge. Some fillers are difficult to detect, and turquoise treated with inorganic substances exhibits nondescript reactions to routine and nondestructive examinations.

The pores of untreated and electrochemicaltreated turquoise have been quantitatively analyzed in previous reports with the gas adsorption method and the X-ray micro-CT 3D imaging technique (Li et al., 2016; Lu et al., 2020). However, few reports have directly revealed the differences in characteristics and porosity between untreated and resin-filled turquoise (Liu et al., 2019; Xu and Yang, 2019).

This research systematically reports on resin filling techniques and the characteristics used to identify them. It also provides new insight into turquoise pores, as well as variations in the distinct features of untreated and resin-filled turquoise, namely their color and porosity. Additionally, this research aims to demonstrate the influence of pore filling on turquoise durability and appearance. The results provide valuable guidelines for detection and treatment.

\section{MATERIALS AND METHODS}

Samples. Turquoise specimens were prepared by different methods and labeled as group A, B, or C. Samples in group $\mathrm{A}$ and those in group $\mathrm{C}$ from a rough sample were provided by local dealers. Group B samples were purchased from a local dealer.

Group A. A set of 342 pieces of turquoise with various colors, sizes, and shapes were treated with resin and hardener in three different factories located in Zhushan County. Prior to filling, the samples were opaque, with 

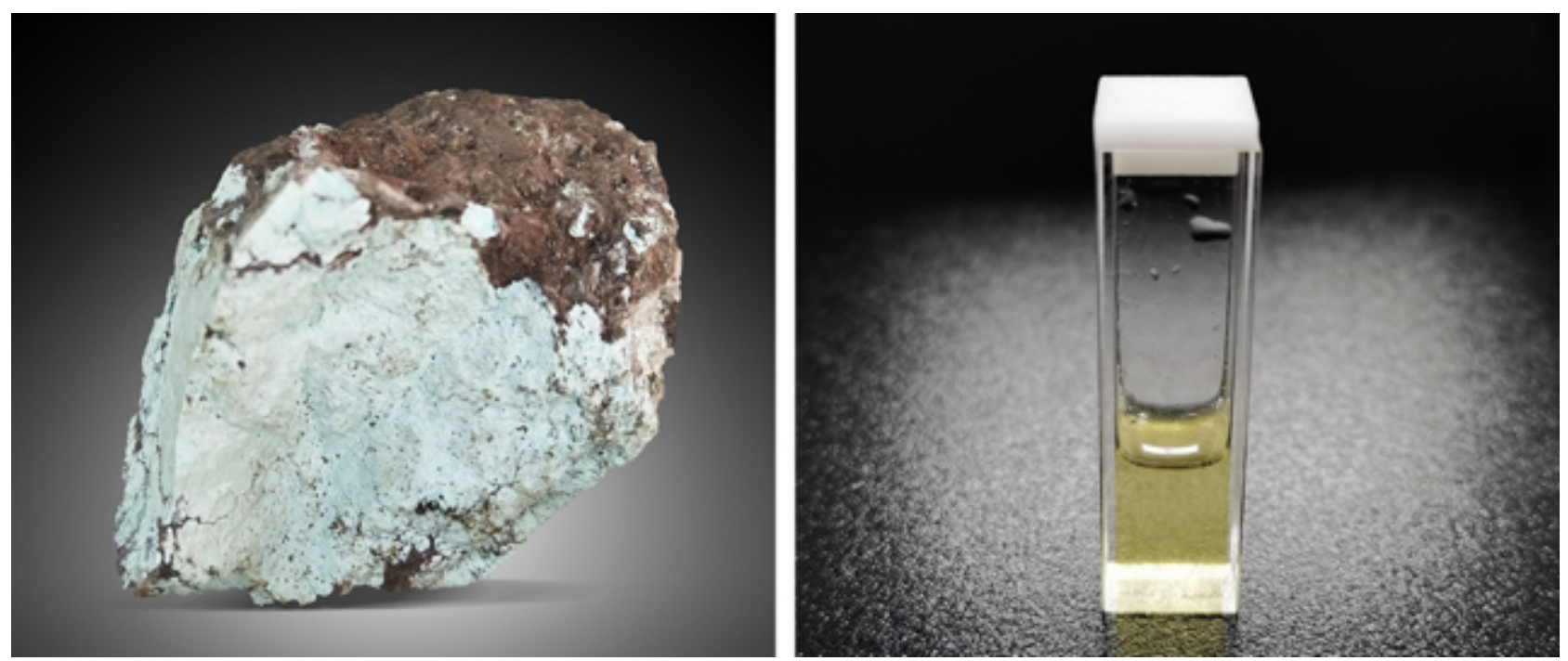

Figure 6. Left: A porous and chalky rough turquoise sample (group C) from Zhushan County (100-150 mm in diameter). Right: The mixed resin/hardener agents used for filling, offered by Bu Tian Sheng Yu Turquoise Co. Ltd. Photos by Ling Liu.

a dull to glassy luster. Their colors ranged from pale to deep blue, green-blue, green, or yellow.

Group B. Twenty circular specimens of turquoise with various specific gravities (2.19-2.84) were selected for pore observation. Each sample was cut in half; one half was treated with resin and hardener to enhance the color, while the other was left untreated for comparison.

Group C. A porous and chalky rough sample (figure 6, left) from Zhushan County was cut into a series of block specimens, but we selected two block samples for testing in this study. These specimens were subsequently divided into two groups: (1) untreated and polished and (2) treated with mixed agents of resin and hardener (hereafter referred to as "resin") (figure 6 , right) for 2-3 days and then polished.

Characterization Techniques. Specific gravity was determined hydrostatically at the gem testing center of the China University of Geosciences (Wuhan) in Zhushan County. Images of all the samples were captured in a light box (D55 light source) under identical conditions to compare changes in color. Each group was characterized by different techniques (table 1).

Environmental scanning electron microscopy (ESEM) (FEI Quanta 200) was performed on the 20 untreated halves (group B), as well as two block specimens (group C). All samples were coated with carbon and tested in a vacuum at a voltage of $20 \mathrm{kV}$.

TABLE 1. Techniques used to characterize the turquoise samples prepared by various methods.

\begin{tabular}{lcccc}
\hline Group & No. of samples & Treatment & Characterization techniques & Purpose \\
\hline A & 342 & Resin filling & Photography & $\begin{array}{c}\text { Comparison and evaluation of quality } \\
\text { before and after treatment }\end{array}$ \\
B & 20 & Untreated and Resin filling & ESEM and photography & $\begin{array}{c}\text { Pore observation and appearance } \\
\text { comparison }\end{array}$ \\
C & 2 & Untreated and Resin filling & $\begin{array}{c}\text { UV fluorescence, 3D } \\
\text { fluoscence, FTIR, ESEM, } \\
\text { and photography }\end{array}$ & $\begin{array}{c}\text { Identification of detection } \\
\text { characteristics and porosity comparison }\end{array}$ \\
\hline
\end{tabular}




\section{Resin Filling Process}

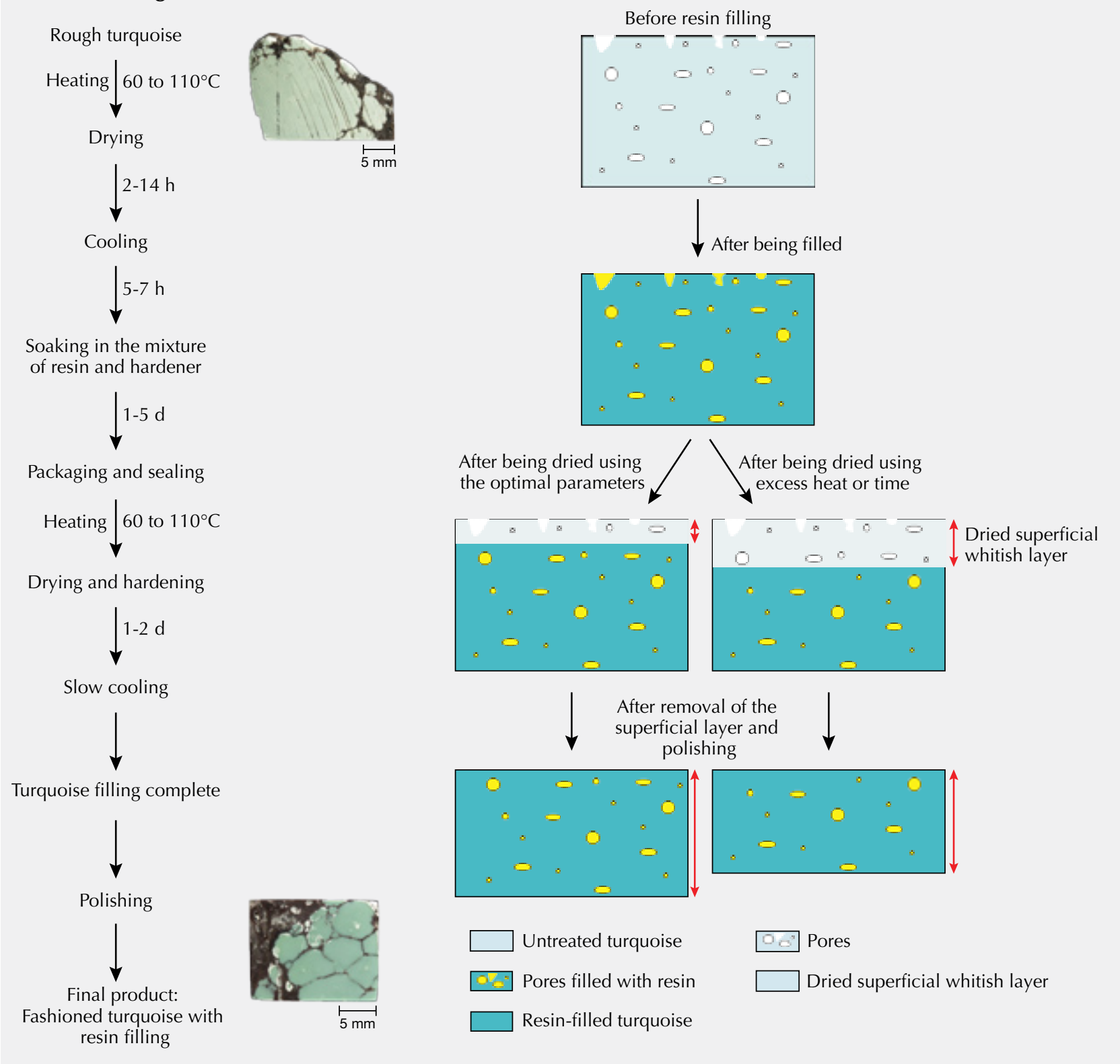

Figure 7. Flowchart (left) and schematic (right) of the process for resin filling of turquoise pores. Illustration by Ling Liu.

Ultraviolet fluorescence was observed under short-wave (SW, $254 \mathrm{~nm}$ ) and long-wave (LW, $365 \mathrm{~nm}$ ) UV radiation. 3D fluorescent patterns of untreated, resin-filled block specimens (group C), and resin were collected by a Jasco FP-8500 spectrofluorometer with a xenon lamp light source. The photomultiplier tube (PMT) voltage was adjusted for sample testing (520 V for untreated and resin-filled turquoise, $550 \mathrm{~V}$ for resin). The emission range $(270-750 \mathrm{~nm})$ was measured with the excitation ranging from 250 to $600 \mathrm{~nm}$ at a response time of 0.5 seconds and scan speed of $2000 \mathrm{~nm} / \mathrm{min}$. The $E_{x}$ and $E_{m}$ bandwidths were set to 5.0 and $2.5 \mathrm{~nm}$, respectively.

Fourier transform infrared (FTIR) spectroscopy was recorded in the range of $400-4000 \mathrm{~cm}^{-1}$ with 64 scans at a resolution of $4.0 \mathrm{~cm}^{-1}$ using a Bruker VERTEX 80 FTIR spectrometer. The spectra of the untreated and resin-filled block specimens from group $\mathrm{C}$, as well as the mixed agent of resin and hardener, were obtained using the $\mathrm{KBr}$ pellet method in transmission mode. 
Resin Filling Process. Resin filling aims to enhance the texture or compactness of natural rough turquoise, which crumbles easily and is difficult to process due to its porous structure. The treatment can improve processability, durability, and stability, while also preventing the absorption of sweat, skin oil, and cosmetics. The procedures for our experiments were as follows (figure 7, left):

1. Preheating and First Drying. Turquoise needs to be dried by preheating in an oven because it is somewhat hygroscopic and contains water. The initial temperature was set at about 60 $80^{\circ} \mathrm{C}$ and maintained for 2-8 hours depending on sample dimensions. Subsequently, the temperature was increased at a rate of $5-20^{\circ} \mathrm{C}$ every 2-8 hours. The optimal temperature was raised to $\sim 110^{\circ} \mathrm{C}$ until all of the absorbed water was evaporated.

2. Cooling. The samples were slowly cooled down to room temperature over 5-7 hours. Turquoise should be protected from sharp dips in temperature, which can be destructive.

3. Soaking. The dried turquoise was soaked in a mixture of resin and hardener for 1-5 days at room temperature without pressure until it was adequately filled, and it was then packaged and sealed.

4. Second Drying for Hardening. Afterward, the samples were placed in an oven for secondary drying and hardening at a preliminary temperature of about $50-90^{\circ} \mathrm{C}$ for about 3.5 hours. The temperature was then increased by 5 $10^{\circ} \mathrm{C}$ every five hours until peaking at $110^{\circ} \mathrm{C}$. After the hardening procedure was completed, the oven was allowed to cool by $20^{\circ} \mathrm{C}$ every 2 hours until reaching room temperature.
5. Finally, the filled turquoise samples were polished to remove the remaining fillers and superficial whitish dried layer to achieve the improved appearance.

The temperatures and durations given here are approximate because the processing factories requested confidentiality. Optimal parameters mattered significantly for resin filling. Temperature and dwell time should be carefully adjusted according to the size and porosity of the turquoise, as excessive heat and durations damage its inner structure. In addition, a whitish dried layer is produced on the surface of the turquoise after the secondary drying process. If the secondary drying stage (for hardening) was too long, material would be wasted as a thick whitish dried layer would form and need to be removed after resin filling (figure 7 , right).

\section{RESULTS}

After resin filling, the treated samples were opaque, with a superficial whitish layer; see figure 7 (right) and figure 8 (center). The fashioned treated turquoise displayed obviously enhanced color and luster after polishing (figure 8).

Changes in Turquoise Color After Resin Filling. Most of the samples showed distinct improvement in color after resin filling (figure 9). The most pronounced color changes were observed in chalky and whitish samples with very high porosity, which turned noticeably more saturated in color after the filling. Those samples that had deep color and compact structure were only slightly modified, with barely perceptible color changes discerned since agents would not easily permeate the more compact turquoise.

Figure 8. Variations in some samples at different stages of resin filling. Untreated turquoise (left), turquoise treated with resin before polishing (center), and turquoise treated with resin and polished (right). Photos by Ling Liu.


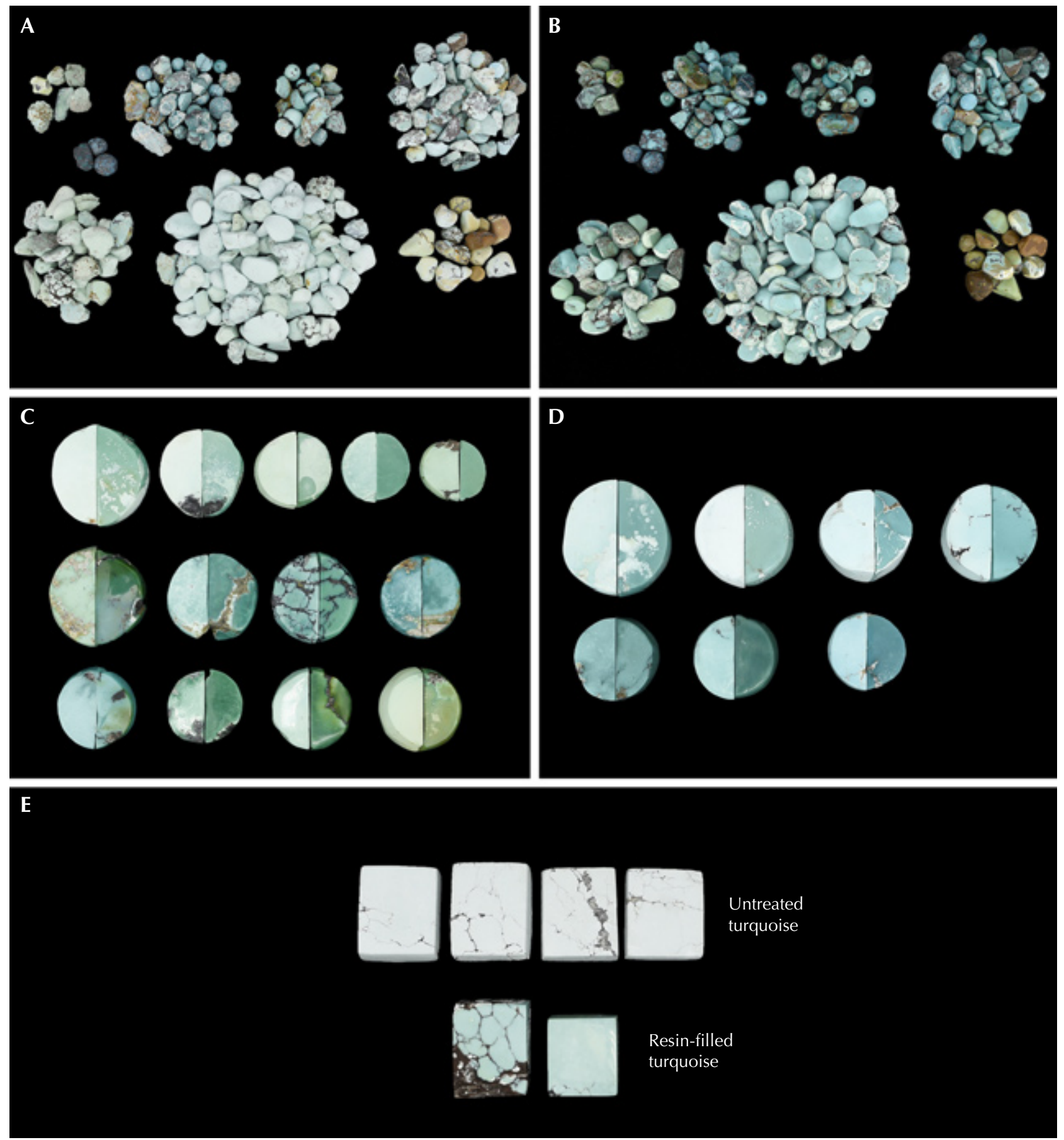

Figure 9. Comparison of untreated turquoise and resin-filled turquoise. Some samples (0.22-2.99 g) of group A before treatment (A) and after (B). C and D: Twenty pieces of turquoise (1.58-4.82 g) were cut in half (group B). The left half of each sample was left untreated, and the right side was treated with resin. Note the deeper and more saturated colors in the resin-filled halves. E: Block specimens (approximately $15 \times 20 \times 5 \mathrm{~mm}$ ) cut from a porous and chalky rough sample for treatment alongside an untreated control group (group C). Photos by Ling Liu.

Changes in Turquoise Porosity After Resin Filling. The dark and irregular areas in the ESEM images of turquoise represent surface pores (figure 10). The pores were unevenly distributed and sometimes crowded together, ranging from 20 to $200 \mu \mathrm{m}$ in diameter with various shapes (circle, triangle, rhom- 

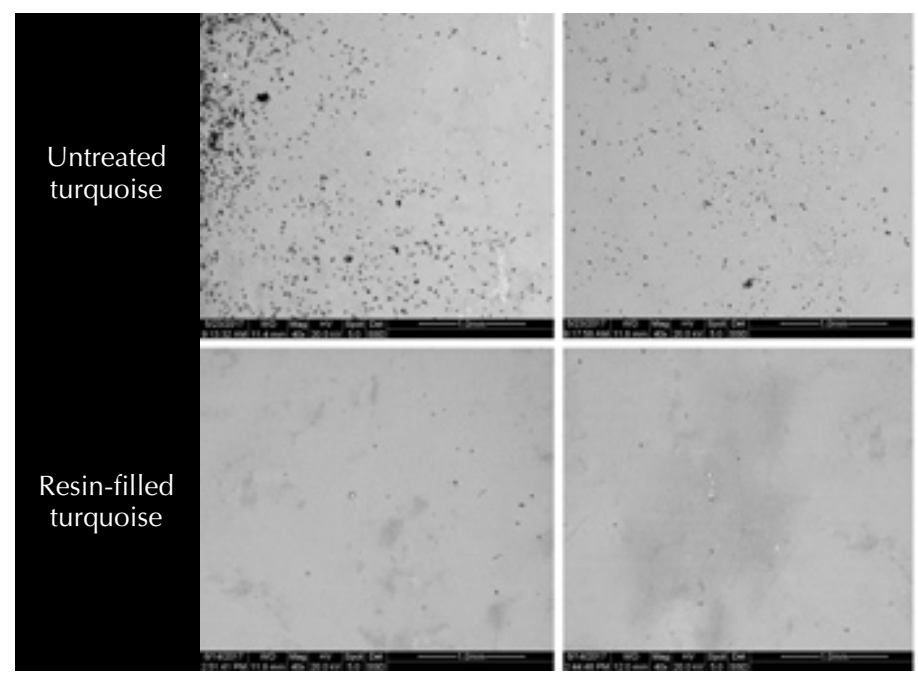

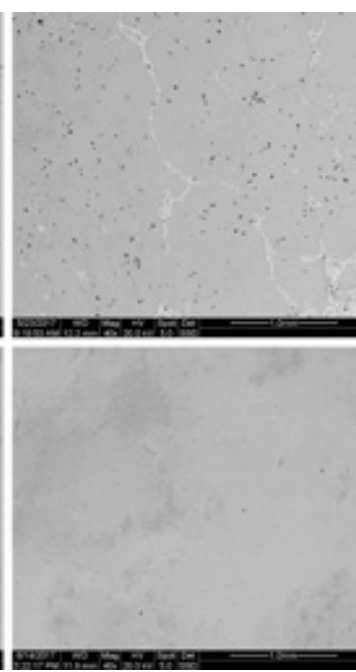

Figure 10. ESEM images showing the distribution of pores in untreated turquoise (top) and resin-filled turquoise (bottom). Note that the untreated turquoise has higher porosity, as evidenced by the dark spots in its ESEM images. Images by Ling Liu. bus, or wormhole). Very few pores were observed in the ESEM images of the resin-filled sample. The untreated turquoise had higher porosity (approximately $1.9 \%$ surface porosity) than the resin-filled one (approximately $0.7 \%$ ). The reduction of porosity confirmed that the resin effectively lowered the porosity and improved the appearance of samples.

Identification of the Treated Turquoise. UV Fluorescence. Untreated turquoise displayed an inert or very weak fluorescence reaction to both short- and longwave UV. Resin-filled turquoise samples showed no fluorescence under short-wave UV radiation but strong blue fluorescence under long-wave UV (figure 11). The resin was inert to short-wave UV radiation but showed strong milky blue fluorescence under long-wave UV (again, see figure 11).

3D Fluorescence Patterns. There were distinct differences between the 3D fluorescence of untreated and resin-filled samples. Untreated turquoise fluoresced very weakly to the full excitation wavelength range (figure 12). The resin-filled turquoise, however, had a strong main emission peak centered at $444 \mathrm{~nm}$ under excitation at $372 \mathrm{~nm}$, as well as a secondary emission shoulder at $460 \mathrm{~nm}$.

Figure 11. Comparative fluorescence reactions of the untreated turquoise, resin-filled turquoise, and resin under SWUV (center) and LWUV (right). Photos by Yuyang Zhang; courtesy of Ling Liu.
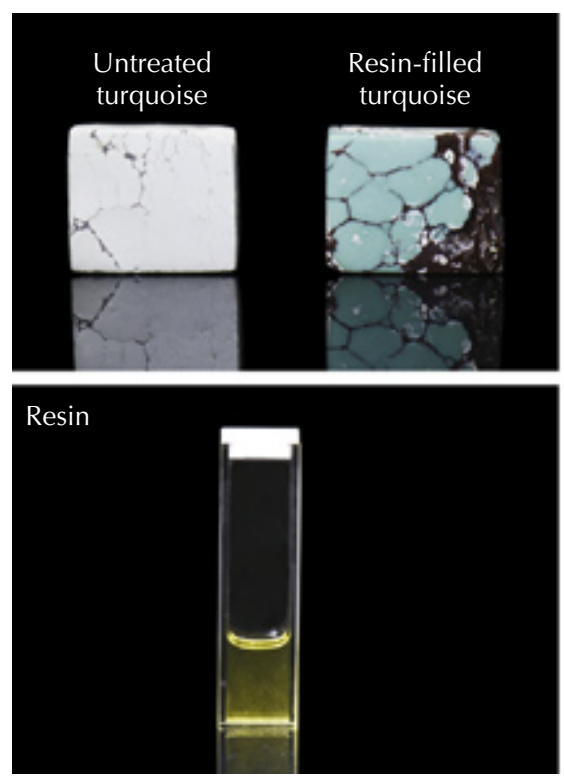
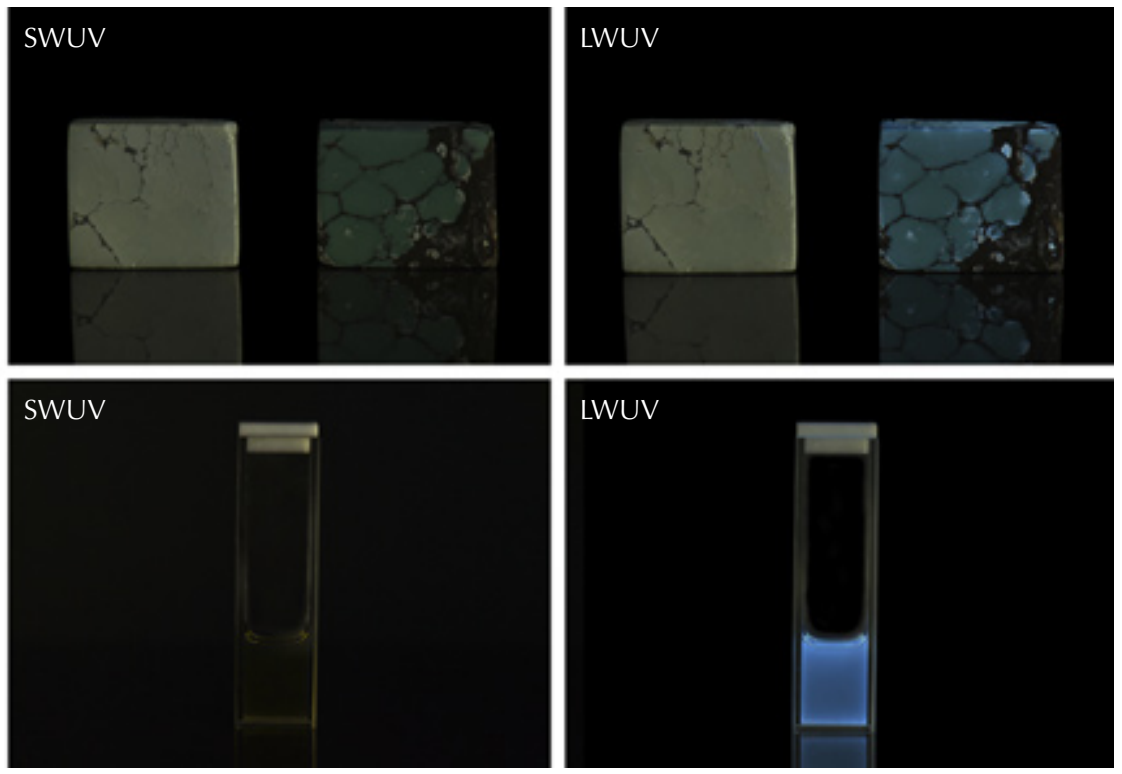

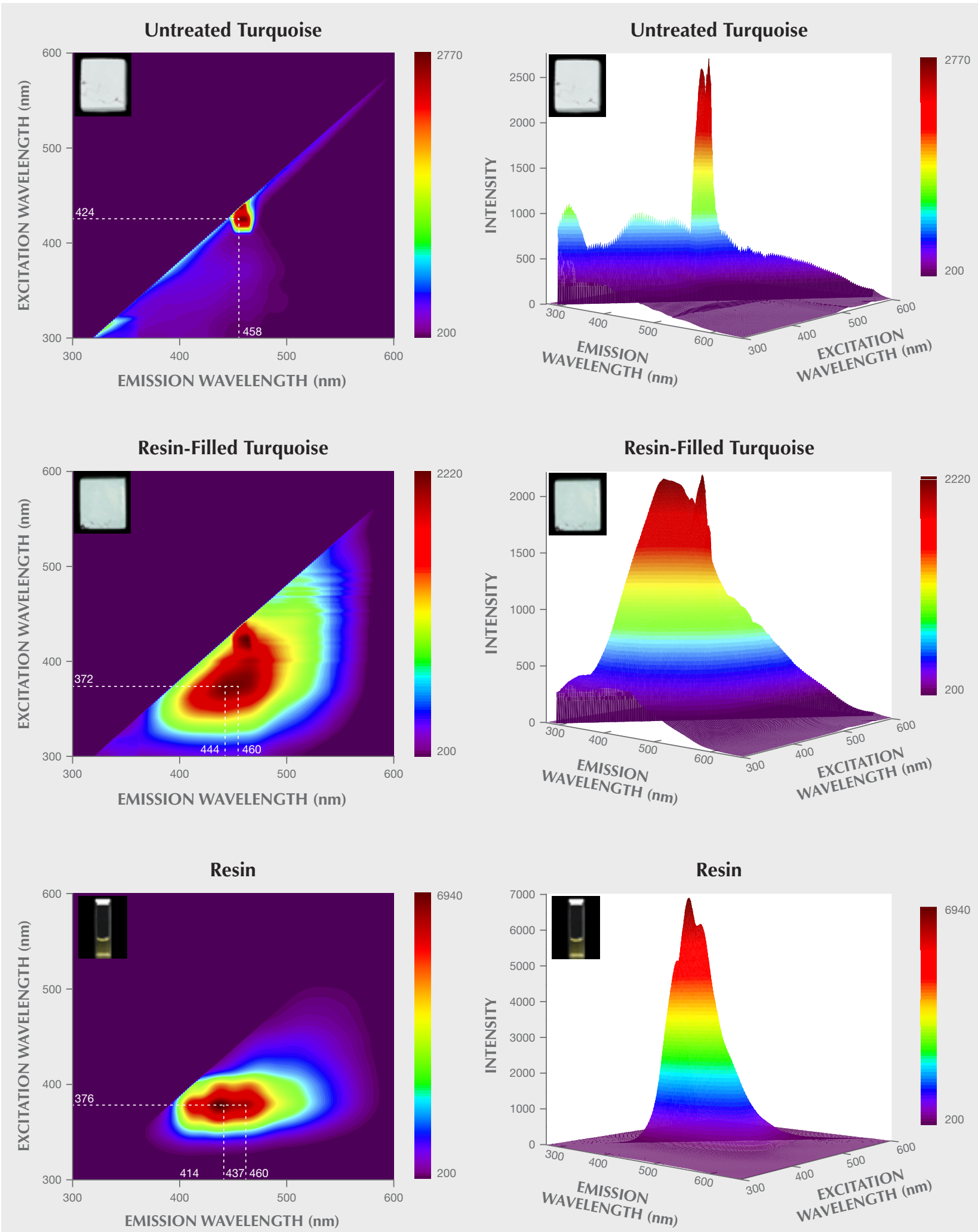

Figure 12. 3D fluorescence patterns of untreated turquoise, resin-filled turquoise, and resin. Note that the emission peak at $458 \mathrm{~nm}$ under $424 \mathrm{~nm}$ excitation in the untreated and resin-filled samples is attributed not to the tested samples but to the instrument. 


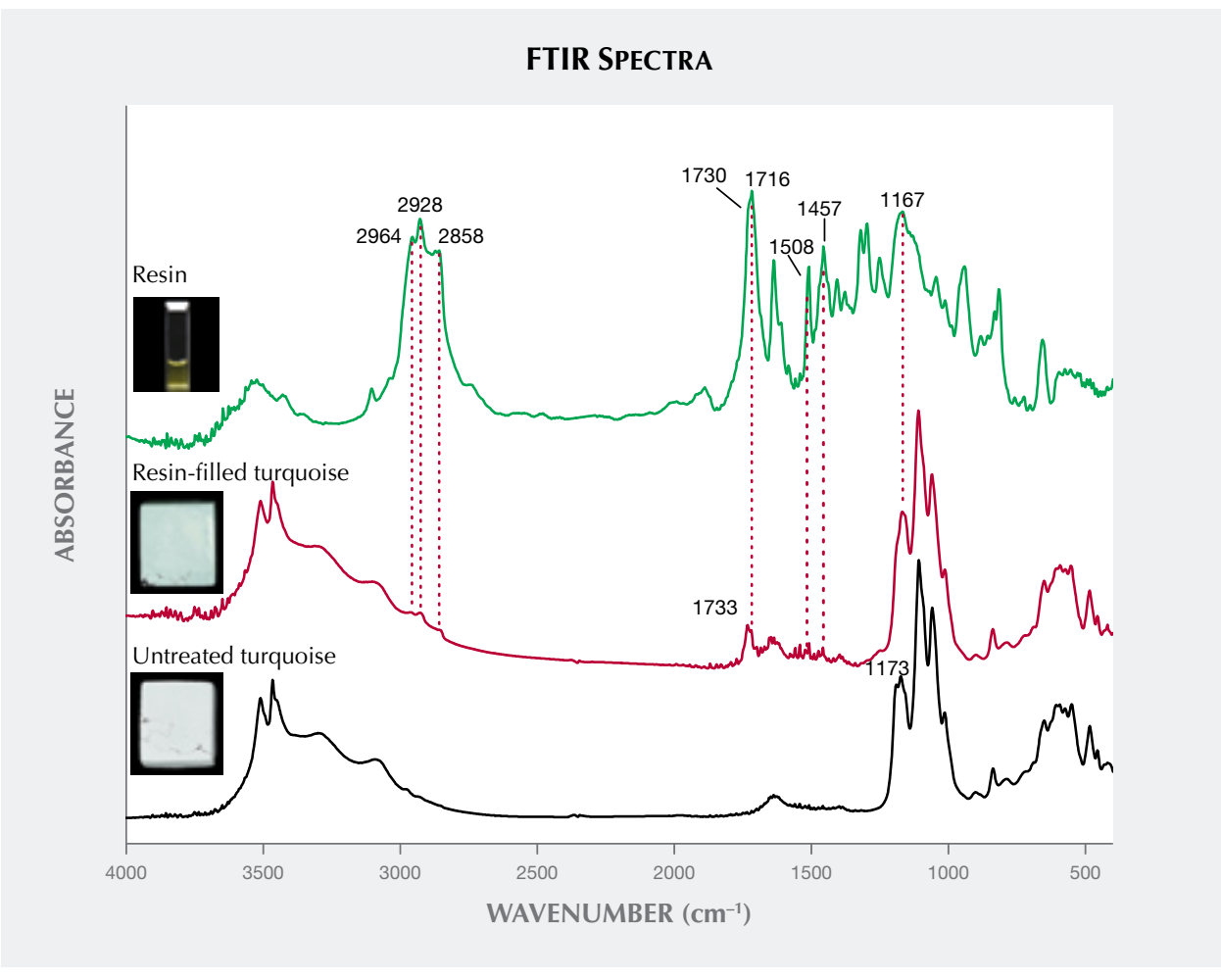

Figure 13. FTIR spectra of untreated turquoise (black line), resin-filled turquoise (red line), and resin (green line). Spectra offset for clarity.

The 3D fluorescence pattern of the resin was also investigated in this study. The pattern exhibited three strong emission peaks centered at 414, 437, and $460 \mathrm{~nm}$ when excited by $376 \mathrm{~nm}$ light. These three strong emission centers occurring in the resin's $3 \mathrm{D}$ fluorescence pattern matched well with those of the resin-filled turquoise. Accordingly, it was assumed that the presence of these strong emission peaks offered proof of resin filling. It should be noted that the varied types and dosages of organic substances used for resin treatment in each factory might alter the 3D fluorescence patterns of the resinfilled turquoise. The 3D fluorescence patterns of various resin-treated turquoise need to be further investigated.

Infrared Spectroscopy. The untreated turquoise showed important bands in two ranges, from 3000$3600 \mathrm{~cm}^{-1}$ and $1800-400 \mathrm{~cm}^{-1}$, which are typical variations of $\mathrm{OH}, \mathrm{H}_{2} \mathrm{O}$, and $\mathrm{PO}_{4}$ according to previous research (Reddy et al., 2006; Chen and Qi, 2007; Chen et al., 2012; Cejka et al., 2015). The spectra of the resin-filled turquoise were characterized by the different combinations of turquoise and resin used in the treatment process. As expected, the filled turquoise samples exhibited additional diagnostic bands of resin at approximately $1733 \mathrm{~cm}^{-1}$ (figure 13), attributable to $\mathrm{C}=\mathrm{O}$ vibration (Lind et al., 1983; Pavese et al., 2005; Chen et al., 2006; Moe et al., 2007). Other weak bands appeared at 2964, $2928,2858,1716,1508,1457$, and $1167 \mathrm{~cm}^{-1}$ in the spectrum of resin-filled turquoise. The resin is responsible for these bands. It displayed prominent bands at 2964, 2928, 2858, 1730, 1716, 1637, 1509, $1455,1405,1377,1319,1296,1251,1167,1044$, 940,815 , and $656 \mathrm{~cm}^{-1}$, as well as other weak bands.

There were notable differences in the fluorescence reactions and FTIR spectra of the untreated and treated turquoise, which offered diagnostic evidence for identifying resin-filled turquoise.

\section{CONCLUSIONS}

Resin filling can effectively improve the appearance of porous rough turquoise. Observations of pore distribution and quantity in both untreated and resinfilled turquoise reveal that most pores can be well filled by resin, resulting in a deeper color without the use of additional colorant. Untreated turquoise fluoresced very weakly to the full excitation wavelengths of light. But the resin-filled turquoise in this research had strong fluorescence under long-wave UV. Under $372 \mathrm{~nm}$ excitation, a strong main emission peak centered at $444 \mathrm{~nm}$ and a secondary emis- 
sion shoulder at $460 \mathrm{~nm}$ occurred in its 3D fluorescence patterns. The filled turquoise had an intense band at $1733 \mathrm{~cm}^{-1}$, and other weak bands in IR spectra as well. Fluorescence reactions and the occurrence of additional FTIR bands related to organic resin provide the evidence required to identify resinfilled turquoise.
Pore filling is an economically worthwhile approach to optimize porous rough turquoise, making it suitable for commercial jewelry or ornaments with high added value. The effectiveness of pore-filling treatment in improving the processability, appearance, and durability of this precious gemstone should be recognized, and it needs to be fully disclosed to the consumer.

\section{ABOUT THE AUTHORS}

Ms. Liu (lingliu0928@163.com) is a PhD candidate at the Gemmological Institute, China University of Geosciences in Wuhan (CUG). Professor Yang (yangc@cug.edu.cn, corresponding author), Associate Professor Li (yanli@cug.edu.cn), and Associate Professor Di are from Gemmological Institute, CUG. Mr. Chong He is a distinguished gemologist at the Gem Testing Center, CUG. Mrs. Jia Liu is a lab manager and Ms. Ruoxi Chen holds a master's degree in gemology from the Gemmological Institute, CUG.

\section{ACKNOWLEDGMENTS}

This research was financially supported by Grant No. 2018YFF0215400 from the National Key R\&D Program of China and Grant No. 20BKG030 from the National Social Science Fund of China. This work was also partially supported by the Gemmological Institute, CUG. The authors sincerely thank Mr. Yang Xu at the Gem Testing Center, CUG for kind assistance. Many thanks to Mr. Haitao He (a manager at Baoyuan Mining Co. Ltd in Zhushan County) and the following companies for generously providing the specimens: Long Fu Turquoise Co. Ltd, Bu Tian Sheng Yu Turquoise Co. Ltd, and Hua Zhou Yi Lan Turquoise Co. Ltd.

\section{REFERENCES}

Bernardino N.D.E., Izumi C.M.S., de Faria D.L.A. (2016) Fake turquoises investigated by Raman microscopy. Forensic Science International, Vol. 262, pp. 196-200, http://dx.doi.org/10.1016/i.forsciint.2016.03.041

Cejka J., Sejkora J., Macek I., Malíková R., Wang L., Scholz R., Xi Y., Frost R.L. (2015) Raman and infrared spectroscopic study of turquoise minerals. Spectrochimica Acta Part A: Molecular and Biomolecular Spectroscopy, Vol. 149, pp. 173-182, http://dx.doi.org/10.1016/j.saa.2015.04.029

Chen Q.-L., Qi L.-J. (2007) Study on the vibrational spectra characters of water in turquoise from $\mathrm{Ma}^{\prime}$ anshan. Journal of Mineralogy and Petrology, Vol. 27, No. 1, pp. 30-35 [in Chinese].

Chen Q.-L., Qi L.-J., Zhang Y. (2006) IR absorption spectrum representation of turquoise, treated turquoise and imitation. Journal of Gems and Gemmology, Vol. 8, No. 1, pp. 9-12 [in Chinese].

Chen Q.-L., Yuan X.-Q., Chen J.-Z., Qi L.-J. (2010a) Study on the treatment turquoise using Raman spectroscopy. Spectroscopy and Spectral Analysis, Vol. 30, No. 7, pp. 1789-1792 [in Chinese].

Chen Q.-L., Yuan X.-Q., Chen J.-Z., Zhou J.-H. (2010b) Structural characteristics of turquoise filled with aluminum phosphate adhesive. Earth Science - Journal of China University of Geosciences, Vol. 35, No. 6, pp. 1023-1028 [in Chinese].

Chen Q.-L., Yin Z.-W., Qi L.-J., Xiong Y. (2012) Turquoise from Zhushan County, Hubei Province, China. GÆG, Vol. 48, No. 3, pp. 198-204, http://dx.doi.org/10.5741/GEMS.48.3.198

Choudhary G. (2010) A new type of composite turquoise. $G \uplus G$, Vol. 46, No. 2, pp. 106-113, http://dx.doi.org/10.5741/GEMS.46.2.106

Deng C.-J., Wang D., Xu B., Bai F. (2009) Research on filling treat- ment of tourmaline. Journal of Gems and Gemmology, Vol. 11, No. 3, pp. 42-43, 58 [in Chinese].

Deng Q., Hu J.M., Wang X., Cao Y., Yang W. (2019) Identification of turquoise with "Iia $\mathrm{Ci}^{\prime}$ treatment. In Proceedings of the China International Gems « Jewelry Academic Conference, Beijing, pp. 263-267.

Filin S.V., Puzynin A.I. (2009) Prevention of cracking in Ethiopian opal. Australian Gemmologist, Vol. 23, No. 12, pp. 579-582

Fritsch E., McClure S.F., Ostrooumov M., Andres Y., Moses T.M., Koivula J.I., Kammerling R.C. (1999) The identification of Zachery-treated turquoise. Ge G, Vol. 35, No. 1, pp. 4-16, http://dx.doi.org/10.5741/GEMS.35.1.4

GAAJ Lab Alert: Lead glass filled ruby (2004) Gemmological Association of All Japan, March 15, https://griapan.ddo.jp/gaaj_ report/2004/gaai_alert-040315en.html

Gambhir R. (2001) Fire opal. Canadian Jeweller, Vol. 122, No. 6 p. 66.

Han W., Lu T.J., Dai H.R., Su J. (2015) Impregnated and dyed turquoise. $G \uplus G$, Vol. 51, No. 3, pp. 343-345.

Henn U., Milisenda C. (2005) Turquoise-Properties and occurrences, imitations and treatments. Gemmologie: Zeitschrift der Deutschen Gemmologischen Gesellschaft, Vol. 54, No. 23, pp. 97-110.

Hu J.M., Wang X., Deng Q. (2019) Study on oiled turquoise. In Proceedings of the China International Gems \& Jewelry Academic Conference, Beijing, pp. 268-272.

Hu Y., Fan L.W., Xue Q.F. (2013) Study on filling treatment and identification characteristics of opal from Ethiopian. Journal of Gems and Gemmology, Vol. 15, No. 2, pp. 32-37 [in Chinese]. Johnson M.L. (2007) Durability testing of filled emeralds. $G \uplus G$, Vol. 
43, No. 2, pp. 120-137, http://dx.doi.org/10.5741/GEMS.43.2.120

Johnson M.L., Elen S., Muhlmeister S. (1999) On the identification of various emerald filling substances. $G \uplus G$, Vol. 35 , No. 2, pp. 82-107.

Kammerling R.C., Koivula J.I., Kane R.E., Maddison P., Shigley J.E., Fritsch E. (1991) Fracture filling of emeralds: Opticon and traditional "oils." $G \uplus G$, Vol. 27, No. 2, pp. 70-85, http://dx.doi.org/10.5741/GEMS.27.2.70

Koivula J.I., Kammerling R.C., Fritsch E. (1992) Gem News: Modern-day turquoise oiling. $G \uplus G$, Vol. 28, No. 2, p. 137.

Li K., Lu T.J., Dai H., Chen H., Ke J., Zhang J. (2016) Quantitative analysis of turquoise pores by gas adsorption. In Proceedings of the 2016 National Mineral Science and Engineering Symposium 2016, pp. 10-12.

Lin X.D., Shen C.Q., Lin Z.Y. (2019) Current status and introduction of electrochemical treatment on turquoise. In Proceedings of the China International Gems ↔) Jewelry Academic Conference, Beijing, pp. 258-262.

Lind T., Schmetzer K., Bank H. (1983) The identification of turquoise by infrared spectroscopy and X-ray powder diffraction. $G \uplus G$, Vol. 19, No. 3, pp. 164-168, http://dx.doi.org/10.5741/GEMS.19.3.164

Liu J., Yang M.X., He C., Cao F.F. (2019) Filled turquoise and its corresponding filling solution. Journal of Gems and Gemmology, Vol. 21, No. 5, pp. 56-64 [in Chinese].

Lu T.J., Dai H., Tian G.F., Li K., Zhang J., Chen H., Ke J. (2020) Quantitative analysis of pore characteristics of natural and electrochemically treated turquoises based on gas adsorption method and X-ray micro-CT 3D imaging technique. Earth Science Frontiers, Vol. 27, No. 5, pp. 247-253, http://dx.doi.org/10.13745/j.esf.yx.2020.5.51 [in Chinese].

McClure S.F., Smith C.P., Wang W., Hall M. (2006) Identification and durability of lead glass-filled rubies. Ge) G, Vol. 42, No. 1, pp. 22-36, http://dx.doi.org/10.5741/GEMS.42.1.22
McClure S.F., Kane R.E., Sturman N. (2010) Gemstone enhancement and its detection in the 2000s. GeG, Vol. 46, No. 3, pp. 218-240, http://dx.doi.org/10.5741/GEMS.46.3.218

Moe K.S., Moses T.M., Johnson P. (2007) Polymer-impregnated turquoise. $G \uplus G$, Vol. 43, No. 2, pp. 149-151, http://dx.doi.org/10.5741/GEMS.43.2.149

Pavese A., Prosperi L., Dapiaggi M. (2005) Use of IR-spectroscopy and diffraction to discriminate between natural, synthetic and treated turquoise, and its imitations. Australian Gemmologist, Vol. 22, No. 8, pp. 366-371.

Reddy B.J., Frost R.L., Weier M.L., Martens W.N. (2006) Ultraviolet-visible, near infrared and mid infrared reflectance spectroscopy of turquoise. Journal of Near Infrared Spectroscopy Vol. 14, No. 4, pp. 241-250, http://dx.doi.org/10.1255/jnirs.641

Schwarzinger B., Schwarzinger C. (2017) Investigation of turquoise imitations and treatment with analytical pyrolysis and infrared spectroscopy. Journal of Analytical and Applied Pyrolysis, Vol. 125, pp. 24-31, http://dx.doi.org/10.1016/j.jaap.2017.05.002

Shen C.Q., Lin X.D., Lin Z.Y. (2018) Colour discussion on turquoise optimized by electrochemical method. Journal of Gems and Gemmology, Vol. 20, No. 4, pp. 16-22 [in Chinese].

Xu Y.F., Di J.R. (2018) Gemological identification of natural turquoise and treatment turquoise in Hubei. Acta Petrologica et Mineralogica, Vol. 37, No. 4, pp. 646-654 [in Chinese].

Xu Y.T., Yang M.X. (2019) Filling material and characteristic of polymer-impregnated turquoise in Anhui province. Journal of Gems and Gemmology, Vol. 21, No. 1, pp. 20-30 [in Chinese].

Zhou J.-H., Yuan X.-Q. (2008) Study on modification of loose turquoise by inorganics filling and cementation. Journal of Gems and Gemmology, Vol. 10, No. 3, pp. 31-35, 53 [in Chinese].

Zuo R., Dai H., Jiang X.P., Zhang Q., Zhou Y. (2017) Infrared spectral features of turquoise filled with acrylic polymer. Geology of Anhui, Vol. 27, No. 3, pp. 222-224, 236 [in Chinese].

For online access to all issues of GEMS \& GEMOLOGY from 1934 to the present, visit: 